\title{
La permanencia del pasado: lo clásico en el tiempo
}

\section{Carlos Oliva Mendoza}

\author{
A Miguel Orduña \\ Clásico no es un libro (lo repito) que \\ necesariamente posee tales o cuales méritos; \\ es un libro que las generaciones de los \\ hombres, urgidas por diversas razones, leen con \\ previo fervor y con una misteriosa lealtad.
}

J. L. Borges

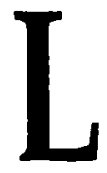

\section{a tradición en la época moderna}

Dentro de los pocos privilegios que tiene la falta de impacto de la teoría dentro de las sociedades contemporáneas está el de la apertura terminológica, que no es sino un reflejo de la crisis interna de los intentos por hacer teoría sobre la realidad. Cuando no es claro el advenimiento del progreso, y su consecuente y necesaria guía teórica y metodológica, entonces: ¿con qué fines y desde qué razón histórica se hace teoría? La pluralidad de respuestas a tales preguntas hace que el hecho de pensar la realidad destroce, literalmente, las empresas de investigación y sus finas estructuras conceptuales y críticas. En ese extravio de la razón histórica, de su implacable autoconciencia y de su instrumento preferido, la crítica, el portentoso paisaje que nos aseguraba el progreso de todos vuelve a ser "la ruina del tiempo". Cuando observamos la situación actual,' como resultado de la zaga triunfante de la razón, del progreso, de la globalidad mundial y de la tecnologización en la vida, es cuando se rompe el par conceptual que prefirió la

' Solamente tres datos que hablan un poco de la situación actual: más del $40 \%$ de la población de América Latina vive bajo el índice del nivel de pobreza, existen en el mundo más de mil millones de analfabetas y entre trece y catorce millones de niños mueren por enfermedades que pueden ser prevenidas si hubiera una mejor distribución de la riqueza (véase, Excelsior, 12 de marzo de 1998). 
modernidad, la mediación utópica entre el presente y el futuro, y observamos la "indeseable" permanencia del pasado en el presente. Es en ese contexto que vuelve hablarse de la importancia de pensar desde la tradición y sus formas de manifestación y condicionamiento de la vida cotidiana.

Pese a que el tema de la tradición es cada vez más discutido dentro de las instituciones académicas y que se produce cada vez un mayor número de textos donde se trata de analizar el complejo factum de la tradición, ${ }^{2}$ parece que siempre es necesaria una justificación al hecho de jugar con tan corrosivo término. El fenómeno tiene dos posibles explicaciones. La primera, es la permanencia de determinados prejuicios de la llustración que se encarnan en la mismas dinámicas de creación y transmisión del conocimiento dentro de las instancias educativas. Una noción como la de tradición hace perder piso al principio elemental del método y su compleja dialéctica de formación de objetos y posterior justificación epistémica de los mismo objetos. La tradición no puede transformarse en un objeto de conocimiento que pueda ser abarcado por completo. La fórmula guía del conocimiento moderno, donde un sujeto proyecta y fundamenta un objeto de conocimiento, es algo absurdo para pensar el fenómeno de la tradición. La tradición no es externa al sujeto que conoce, ella misma señala las formas específicas en que una comunidad conoce, y más aún, lo que entiende esa comunidad por conocer. La segunda explicación se sigue de la anterior; plantear este tipo de nociones implica una constante tensión con los conceptos clave del racionalismo mo-

\footnotetext{
${ }^{2}$ Una referencia, mínima, sobre todo de filosofía para el tema de la tradición es la siguiente: Mariflor Aguilar Rivero, Confrontación, crítica y hermenéutica. Gadamer, Ricoeur, Habermas. México, UNAM-Fontamara, 1998; Hans-Georg Gadamer, "Los prejuicios como condición de la comprensión", en Verdad y método I. Salamanca, Sígueme, 1993, pp. 344-360; Anthony Giddens, "La vida en una sociedad post-tradicional", en Ágora, núm. 6, verano de 1997, pp. 56-109; Jürgen Habermas, "El enfoque hermenéutico" y "La pretensión de universalidad de la hermenéutica (1970)", en La lógica de las ciencias sociales. Trad. de Manuel Jiménez Redondo, México, Rei, 1993 , pp. 228.256 y pp. 277.306, respectivamente; Alasdair Macintyre, "La racionalidad de las tradiciones", en Justicia y racionalidad. Barcelona, 1994, pp. 331-349; Karl R. Popper, "Hacia una teoría racional de la tradición", en Conjeturas y refutaciones. El desarrollo del conocimiento científico. Trad. de Néstor Miguez. Barcelona, Paidós. 1979, pp. 142-159; Paul Ricoeur, "Hermeneutics and the Critique of Ideology", en Hermeneutic and the Human Sciences. Trad., ed. e introd. de John B. Thompson. Cambridge, Universidad de Cambridge, 1981, pp. 63.100; Ambrosio Velasco Gómez, "El concepto de tradición en filosofia de la ciencia y en la hermenéutica filosófica", en Racionalidad y cambio científico. México, Seminario de Problemas Científicos y Filosóficos, UNAm-Paidós, 1997, pp. 157-178; Georgia Warnke, Gadamer: Hermeneutics, Tradition and Reason, Universidad de Stanford, 1987. $206 \mathrm{pp}, \mathrm{y}$ Peter Winch, Comprender una sociedad primitiva. Trad. de José Nicolau y Gloria Llorens. Madrid, Paidós, 1994. (Pensamiento Contemporáneo, 33)
} 
derno. Hablar de tradición, necesariamente es hablar, en cierta medida, contra la figura de la conciencia, contra la acción del método, y ser cautelosos ante la soberbia de la crítica racional frente a la realidad. ${ }^{3}$ Además, el uso radical de la noción de tradición implica proponer un ideal de verdad diferente de aquel que guía la modernidad dominante: la verdad que va desde el sinuoso camino cartesiano en busca del yo que fundamenta la realidad, hasta el complejo, y no menos sinuoso, camino que sigue Hegel para encontrar el fundamento de lo real en la razón y, a su vez, de lo racional en lo real. Justifiquémonos entonces.

La tradición es, como ha dicho Gadamer, un material de la realidad; pero además es básicamente una forma constitutiva del pasado que se manifiesta en la realidad presente. En ese sentido existen tres rasgos fundamentales a la tradición: el contexto, la alteridad y la escasez. Toda tradición es, a la vez, una historia contextual, porque toda tradición se manifiesta, y de hecho sólo es posible, en su recepción, es decir, en su interpretación presente. Justo por ese movimiento que hace la tradición es que se vuelve, como también indicara Gadamer, un tú que nos interpela. Sin embargo, el punto central no es distinguir a la tradición solamente como un otro, sino como el otro que a la vez nos constituye. El punto fundamental de mediación entre la tradición con el presente es el momento en que cada uno de nosotros va siendo desde lo otro, desde una comunidad cultural y lingüistica previa, que tiene una de sus manifestaciones en la tradición. De todo esto no debe inferirse un círculo clauso, donde la tradición ya prefigure lo que uno puede ser mientras niega cualquier acercamiento a otras tradiciones constituidas. Por el contrario, el movimiento con nuestra tradición, esto es, el movimiento de identidad y diferencia con el pasado que nos constituye, ya implica potencialmente el mismo movimiento hacia otras tradiciones. Comprender verdaderamente nuestra tradición es comprender su pluralidad y diversidad de manifestaciones en el tiempo, y comprender, en última instancia, la existencia de otras tradiciones. Por último, la referencia a la escasez tiene dos sentidos, por una parte es una noción de economía histórica, el mundo de la escasez es un mundo previo al mundo de la acumulación de riquezas donde necesariamente vivir implicaba la permanencia de una comunidad. Con el avance de la técnica y de una racionalidad instrumental, llevada hoy en día

${ }^{3}$ Una tesis fundamental del racionalismo moderno es aquella que señala que mediante un proceso crítico y reflexivo podemos abandonar la influencia "ciega" de la tradición; por ejemplo, cuando Descartes señala en las Meditaciones la necesidad de abandonar la noción de creencia por su pluralidad de sentidos y su falta de determinación en un sujeto. Frente a esa idea, regresar a nociones como la de tradición ya implica un ejercicio crítico frente a la idea del sujeto racional que puede conocer, por si mismo, el funcionamiento social. 
hasta el frenesi monetario, esa comunidad fue definitivamente sustituida, entre los siglos Xvil y $\mathrm{xxx}$, por la figura de la nación y los lazos comunitarios con el mundo por fenómenos tan extraños como el llamado mercado mun. dial. En ese sentido, la trađición implica aún hoy una manifestación comunitaria, sus formas de transmisión de conocimiento y de creación no pueden ser abarcadas por el proceso de racionalidad y cientificidad de las sociedades modernas. ${ }^{4}$ En segundo lugar, la referencia a la escasez es filosófica. En tanto la tradición es una parte del pasado nunca puede estar plenamente en el presente, nunca alcanzamos a formular sobre ella una interpretación definitiva y sistemática para traerla totalmente al presente y trascenderla. En ese sentido, la tradición nos remite a la escasez primigenia de hombres y mujeres, la de la finitud radical e insalvable con la que se interpreta el mundo.

Trabajar, pues, sobre la idea de tradición implica, en el fondo, encontrar un fenómeno que a la vez que nos trasciende nos permite otro tipo de acercamiento a la formación de discursos históricos mediante el replanteamiento de la noción de conciencia, del discurso crítico de la modernidad y del ideal de verdad. Todo lo cual tendrá que hacerse desde una historia consciente de que sus condiciones de posibilidad no están en ella misma, sino en el contexto, en la finitud y en la alteridad.

\section{El problema de lo clásico: tradición o tradicionalismo}

Después de las anotaciones realizadas habrá que indicar el tema y el objetivo del presente trabajo. El motivo del texto es el de la manifestación de lo clásico, y su objetivo es intentar responder a la pregunta si toda tradición tiene una forma normativa de manifestación en el presente que se realiza como la mediación histórica que realiza lo clásico. Hemos seguido, en nuestro intento por señalar algunos rasgos manifiestos de la tradición, a Gadamer. El problema que nos ocupa tiene la misma fuente principal, la indagación de Gadamer sobre el modelo de lo clásico referido a la tradición. El problema de lo clásico va más allá de su simple enlace con la tradición. El tema de lo clásico en Gadamer es apenas una intuición que se va a desbordar en toda su

\footnotetext{
${ }^{4}$ En otro texto, "La hermenéutica de la tradición en la época de la reflexión crítica", hemos intentado aclarar que no todo proceso de acumulación de conocimiento y de transmisión del mismo puede ser llamado propiamente tradición. En ese sentido seguimos a Heidegger en su noción de investigación. Lo que se produce den. tro de una sociedad moderna, que se destaca por la figura omnipresente de la subjetividad y el proceso de tecnologización y capitalización de la vida, es un proceso de investigación que tiene sus códigos de creación y reproducción, pero no es una tradición.
} 
obra posterior a Verdad y método I, bajo otra forma, como uno de los temas centrales de su propuesta hermenéutica: la interpretación del arte como forma pasada y, por lo tanto, su necesaria exclusión en la formulación de los conceptos últimos a los que conduce la razón absoluta.

En una primera interpretación el enlace de la tradición y lo clásico indicaría, dentro de la propuesta de Gadamer, la existencia de un movimiento de fundamentación que justamente descansaría en la identidad entre lo clásico y la tradición. Por ejemplo, me parece que es ese el sentido de la interpretación de Mariflor Aguilar cuando escribe:

[...] a partir de la recuperación del círculo hermenéutico heideggeriano y del consiguiente planteamiento de la proyección inicial del sentido, se da un segundo paso explicando dicha proyección considerándola como enraizada en la "situación" del intérprete, es decir, en su contexto. Si estos dos pasos se quedaran sólo en la propuesta, se corre el riesgo de incurrir en subjetivismo, por lo que se debe de dar el paso tercero que consiste en anclar el proceso completo en la historia, con lo cual lo que se introduce en el círculo no son ya nuestras ocurrencias y preocupaciones provisionales ni nuestro entorno inmediato, sino la tradición histórica con las características de lo clásico. ${ }^{5}$

Dicha interpretación deja una pregunta abierta, ¿cuáles son las características de lo clásico? Una gran parte de los exégetas de Gadamer coinciden en el hecho de que tales características serian aquellas que se identifican con el tradicionalismo, esto es, las tradiciones serían en sí mismas autoritarias e irracionales, pobladas de jerarquías, de dogmas, de creencias sin fundamentos racionales, etcétera. De hecho, la única manera de recuperar la tradición sería encontrar en su interior un proceso racional que no fuera muy diferente del proceso racional de la modernidad dominante, es decir, un proceso crítico y reflexivo que se exprese a través de sujetos constituidos, ya sea social o individualmente. ${ }^{6}$ Dicha interpretación tiene uno de sus dogmas fundamentales en creer que toda tradición implica una autoridad que siempre es despótica, esto es, que a través de la tradición hay un proceso de autoritarismo irracional sobre los sujetos. Refutar ese argumento implica mostrar que no toda autoridad puede ser descalificada y que, precisamente, existen diversas posibilidades de racionalidad alternativas a la racio-

${ }^{5}$ M. Aguilar Rivero, Confrontación, crítica y hermenéutica. Gadamer, Ricoeur, Habermas, pp. 137.138.

"Véase al respecto $\mathrm{J}$. Habermas, "La pretensión de universalidad de la hermenéutica (1970)", en La lógica de las ciencias sociales, pp. 228-256 y A. Macintyre, "La racionalidad de las tradiciones", en Justicia y racionalidad, pp. 331.349. 
nalidad unívoca que descalifica desde su tribunal a formas tradicionales de la vida cotidiana. Uno de los intentos del presente trabajo será mostrar que las características normativas de lo clásico son radicalmente opuestas a las del tradicionalismo y que justo la mediación de la tradición con el presente, bajo la forma de lo clásico, es la que posibilita, como una norma, la apertura interpretativa.

\section{El thelos de la historia y su camino inverso}

En primer lugar hagamos algunas breves e hipotéticas anotaciones sobre el movimiento de sistema que se encuentra en la propuesta de Gadamer y su dependencia y distancia del sistema hegeliano. El tema de lo clásico en Gadamer abreva directamente de la historia y la filosofia de la estética de Hegel, pero no sólo eso, en general a medida que pasó el tiempo después de la publicación de Verdad y método I (1960), Gadamer mismo fue aclarando nociones clave en referencia a Hegel. En principio, Gadamer reconoció dos críticas con respecto a su filiación con Hegel. La primera, es respecto al uso que hace el hermeneuta de los medios lingüísticos-conceptuales por fuera de los contextos sistemáticos de la obra de Hegel. La segunda, que más bien es una autocrítica, se refiere al debate, "sin duda insatisfactorio", dice Gadamer, que se da con Hegel en Verdad y método $I^{7}$ De hecho, si uno revisa en forma retrospectiva la obra de Gadamer, se observará que en Verdad $y$ método $I$ existe una serie de intuiciones respecto a problemas fundamentales que sólo en la obra posterior alcanzarán una formulación completa. Sin embargo, el problema central ya está planteado en la obra más importante de Gadamer. El problema es si la diferencia fundamental entre la conciencia hermenéutica y la conciencia de la razón histórica puede ex. presarse con las mismas herramientas conceptuales y lingüísticas que usó la filosofia de la conciencia en su momento más importante que es la obra de Hegel, o más aún, si la reflexión hermenéutica puede alcanzar una diferencia cualitativa con la reflexión crítica al seguir utilizando las nociones centrales de historia y conciencia. Nociones que desde la filosofía clásica de la conciencia impondrian, a través de una razón unívoca, una sola interpretación, una sola conciencia, del proceso histórico.

Uno de los puntos más importantes en torno a las posibilidades de la hermenéutica contemporánea está en el momento en que Gadamer toma posición frente a la Fenomenología del espíritu:

${ }^{7}$ Cf. H.-G. Gadamer, "Réplica a Hermenéutica y critica de la ideología (1971)", en Verdad y método II. Salamanca, Sígueme, 1993. 
Ser histórico quiere decir no agotarse nunca en el saberse. Todo saberse procede de una predeterminación histórica que podemos llamar con Hegel "sustancia", porque soporta toda opinión y comportamiento subjetivo y en consecuencia prefigura y limita toda posibilidad de comprender una tradición en su alteridad histórica. Desde esto la tarea de la hermenéutica filosófica puede caracterizarse como sigue: tiene que rehacer el camino de la fenomenología del Espíritu hegeliana en cuanto que en toda subjetividad se muestra la sustancialidad que la determina. ${ }^{8}$

Como posteriormente diría Gadamer, el hecho de leer retrospectivamente la Fenomenología implica una crítica a la idea del saber absoluto, es decir, a la determinación teleológica del movimiento dialéctico que describe Hegel $y$, en ese mismo sentido, la crítica alcanza la reconstrucción histórica donde el "curso gradual de las figuras del espíritu aparece diseñado en cierto modo desde la óptica de su perfección y no es derivable de su origen". 9 Parecería, pues, quedar clara la diferencia cualitativa entre Hegel y Gadamer, mientras que en el primero la dialéctica conduce a toda experiencia a configurarse como perfecta en el momento en que se vuelve absoluta, en la idea del segundo, nunca podría alcanzarse la perfección del saber absoluto, y como lo señalara puntualmente Gadamer, la única aspiración de perfección sería la del movimiento hacia una nueva experiencia. Sin embargo, nada de lo anterior cancela, de la perspectiva de Gadamer, a la razón, a la conciencia y a la autoconciencia como los elementos de construcción de una historia que aspira siempre a la apertura de la experiencia, es decir, a la apertura al otro.

Pero permítaseme hacer otra interpretación del camino inverso que propone Gadamer respecto de las figuras del espíritu. Mediante los elementos de construcción de la historia que hemos mencionado se logra finalmente arribar a determinados conceptos sobre la misma historia. A través de tales instrumentos se va desvaneciendo la original inadecuación perceptiva del mundo. Entre la intuición sensible e intelectual y la elaboración certera y fija del concepto vence la segunda opción. En ese sentido, no dejan de ser sorprendentes aquellas palabras de Borges donde señala que "Vemos y oímos a través de recuerdos, de temores, de previsiones [...]. Nuestro vivir es una serie de adaptaciones, vale decir, una educación del olvido". ${ }^{10}$ De la misma forma parecen funcionar las figuras que concretan la historia en el senti-

${ }^{8}$ H.-G. Gadamer, Verdad y método I, p. 372.

'H.G. Gadamer, "Réplica a Hermenéutica y crítica de la ideología (1971)", en op. cit., p. 261.

${ }^{10}$ Jorge Luis Borges, "La postulación de la realidad", en Obras completas, vol. I. Barcelona, Emecé, 1989, p. 218. 
do hegeliano: recortan la pluralidad de lo real y nos ofrecen lo real, perfecto e inmóvil.

La propuesta de Gadamer no abandona la ruta de la historia idealista que describió el filósofo alemán:

Hegel, ese valiente suabo, afirmó comprender en su propia mente la perfección de toda la historia del pensamiento y del alma de Occidente; más aún, de la historia de la humanidad en general. Abrigaba la convicción de que la historia tocaba en cierto sentido a su fin, ya que había dejado de ser posible toda duda y discusión sobre el principio por el cual discurre la trayectoria de la historia mundial; el camino de la libertad para todos era lo que constituía la razón de la historia. Ésta es la conocida teoría de Hegel, de la que podemos decir que dio a conocer con juicio certero un principio que alcanzó su victoria final con la Revolución francesa pero que en el fondo surgió en el mundo con el cristianismo. Es indiscutible que todo ser humano debe de ser libre y que no deben de existir esclavos ni esclavización de ninguna clase. La historia consiste en el intento de realizar este ideal; así lo enseñó Hegel y por eso sigue adelante la historia mundial en la época de las revoluciones que luchan por esta realización: como la lucha de dominio contra dominio y por la liberación del dominio... una lucha cuyo fin no puede preverse."

Pero, el hecho de regresar, de desandar las figuras del espíritu, no quiere decir que desconozcamos que, como dice Hegel, la libertad de todos constituye la razón de la historia, sino simplemente que detectemos dónde se pervirtió o dónde está la deformación del ideal cristiano y revolucionario, dónde la misma historia se conformó con ser una representación perfecta de lo que nunca podría suceder. Gadamer, con su tesis sobre la Fenomenología, señala con claridad hasta qué punto hay que destrozar la pretensión idealista de la razón y su construcción histórica: hay que partir del sujeto, esto es, declarar como lo primero y más equívoco la subjetividad y regresar a lo que Hegel llamaba sustancia, que no es otra cosa que lo que nos prefigura para después ser sujetos autónomos y que evidentemente rebasa la simple formación de la conciencia crítica y racional de la modernidad. Todo eso es, en parte, el hecho de la tradición.

"H.-G. Gadamer, "EEl fin del arte?", en La herencia de Europa. Trad. de Pilar Giralt. Barcelona, Península, 1990, pp. 66-67. 


\section{Los rasgos fundamentales de lo clásico}

Las figuras del espíritu tienen su representación histórica, esto es, tienen una comprobación empírica en determinadas épocas de la historia de la humanidad, según Hegel. De tal forma que en el desarrollo de las distintas sociedades existe una verdad alcanzada por las representaciones artísticas, verdad superada por las representaciones religiosas que finalmente alcanza la última verdad posible en el discurso filosófico. El arte, para Hegel, tiene tres momentos históricos: el simbólico, el clásico y el romántico. No hay más arte. Después de esto, el arte se agota y sólo puede ser superado desde la religión. Cuando Gadamer propone recorrer hacia atrás la formación de las figuras del espíritu, esto implica también encontrar los modelos de la comprensión en formaciones pretéritas y por lo tanto deficientes dentro del esquema general de la Fenomenología. De ahí que Gadamer no postule como ejemplo a seguir, en la comprensión del fenómeno de la tradición, al romanticismo que representa ya un modelo más perfecto dentro de las representaciones artísticas que el ejemplo de lo clásico. Pero el movimiento va más allá, buscar un modelo dentro de las representaciones artísticas implica también negar la posibilidad religiosa o filosófica como guía canónica y perfecta de la interpretación de la tradición. El arte es un momento pretérito en comparación a la religión y a la filosofía porque no alcanza la verdad interna o argumentativa de éstas. No es pretérito en el sentido de que se encuentre atrás de nosotros en el tiempo, sino porque nunca logra aprehender la totalidad de lo real y por eso las representaciones artísticas nunca están de forma absoluta en el presente. El arte siempre requiere una interpretación presente a partir de lo que nos dice el pasado. La filosofia, en el sentido del sistema hegeliano, alcanza un momento en que sólo es necesaria la interpretación de ella consigo misma, por eso se vuelve absoluta en un momento presente, ya nada es re-presentación, todo es presencia real y racional. ta representación artística, al igual que la tradición, nunca alcanza a ser contemporánea: nunca está plenamente en el presente.

Pero icuáles son las características propias del arte clásico? En pocos textos están descritas tan perfectamente como en el estudio histórico y filosófico de la dialéctica del arte que realiza Hegel en su Estética. La dialéctica de Hegel, a diferencia de la dialéctica platónica, no es un ejercicio a través del cual se muestra la diversidad de lo real, sino un ejercicio de creación de la realidad a través de la dialéctica. El método usado por Hegel, al igual que la dialéctica de Zenón, implica llevar cada cosa al límite de su abstracción, es decir, se piensa con tal radicalidad la cosa determinada que se elimina cualquier relación de las cosas. Las cosas no tienen que mostrarse en su unidad, sino como una totalidad indivisible. El resultado es una creación impresio. 
nante a través de la descripción. Mientras que la dialéctica platónica busca las múltiples relaciones y determinaciones como justificación de la existencia de las cosas, la dialéctica hegeliana logra ver el potencial de la cosa misma eliminando cualquier relativismo posible en el juicio subjetivo, lo cual a su vez logra mostrar a las contradicciones históricas como absolutas y necesarias.

Las relaciones en la dialéctica de Hegel sólo surgen en el momento en que se agota definitivamente la posibilidad de verdad de cada cosa en sí mis: ma, mientras que en Platón dicha verdad es precisamente la mediación de los géneros en la cosa. La verdad en Platón no depende del sujeto, sino de la develación del movimiento interno que constituye las cosas, de ahí que un sujeto pueda caer en juicios falsos sobre las cosas. En Hegel, la verdad tampoco es un asunto de la subjetividad, ésta tan sólo desarrolla históricamente la conciencia que nos revela la operación de la razón en la historia; la verdad depende de la adecuación de la realidad a la razón y viceversa. Por todo esto, es que muchas de las definiciones de Hegel marcan toda la investigación posterior a él y sintetizan las investigaciones anteriores, porque en el mismo momento que va describiendo va creando, al soldar en una unidad cada fenómeno.

En ese sentido, la definición de lo clásico que hace Hegel sigue mostrando de una manera muy fiel dicho fenómeno:

[...] la belleza clásica tiene como interior la significación libre, autónoma, es decir, no una significación de algo, sino lo que se significa a si mismo y, con ello, también lo que se interpreta a sí mismo. Esto es lo espiritual, que en general se hace objeto de si mismo. En esta objetividad de sí mismo tiene la forma de lo externo, que, como idéntica en su interior, a su vez es inmediatamente la significación de sí misma, y que, en tanto se sabe, se muestra. ${ }^{12}$

El hecho de que sea una definición importante no quiere decir necesariamente que sea clara. Cuando Hegel destaca la autonomía y espiritualidad de todo arte clásico está refiriéndose a los elementos que trascienden al arte simbólico. Este último se ve obligado a representar fenómenos naturales dentro de los cuales se encuentra inmerso y que de hecho dominan y rigen cualquier manifestación de conciencia. El arte clásico, en cambio, implica la primera aparición consciente del espíritu y con ello el término del dominio de lo natural sobre lo humano. El arte clásico es la representación de un poder sereno y consciente de sí frente a la naturaleza:

${ }^{12}$ G. W. F. Hegel, Estética II. Trad. de Raúl Gabás. Barcelona, Península, 1991, p. 11. 
La oposición entre naturaleza y espíritu es de suyo necesaria. Pues, [...] el concepto de espíritu como verdadera totalidad en sí consiste solamente en separarse como objetividad y subjetividad dentro de sí mismo, para salir de la naturaleza a través de esta oposición, y luego, como superador y poder de la naturaleza, ser libre y sereno frente a ella. De ahí que este momento principal en la esencia del espíritu mismo sea también un momento principal en la representación que él se da a sí mismo acerca de sí. Históricamente, esta transición se muestra como un progreso en la transformación del hombre natural para pasar al estado jurídico, a la propiedad, a las leyes, a la constitución, a la vida política. En forma divina y eterna, esto es la representación de la victoria de los dioses espiritualmente individuales sobre los poderes naturales. ${ }^{13}$

Lo que es el arte por medio del arte, nos dice Hegel, termina en la manifestación de lo clásico. La síntesis propiamente del arte, la representación romántica, ya no se consigue en sí misma por medio del arte, sino a través del cristianismo, es decir, a través de una representación religiosa. En ese entendido, en la manifestación de lo clásico, que Hegel llama también el momento del espíritu objetivo, no existe lo que la impronta romántica desarrollará: la radical subjetividad e individualidad. La conciencia de lo clási. co aún es demasiado intuitiva y, por lo tanto, su representación de la divinidad tiene que ser plural, como dice Hegel: "El politeísmo es totalmente esencial al principio del arte clásico" ${ }^{14}$ y no sólo eso, sino que el mismo Hegel indica en forma brillante la imposibilidad de que el arte clásico desarrolle una totalidad sistemática a partir de sus representaciones divinas. Por el contrario, tal pluralidad de formas y poderes impide la jerarquización y el orden definitorio dentro del modelo clásico. Sobre este punto la percepción de Hegel es muy aguda. Lo que se nos muestra en apariencia en el arte clásico es un modelo de representación perfecto, donde todos los atributos de las representaciones están en completa armonía. No se trata de representaciones sublimes, sino de representaciones serenas que tienen un movimiento constante de internarse en si mismas y mostrar dicha interioridad. No hay algo oculto en la representación clásica, lo que se muestra en ella es ella misma. Lo clásico es el momento en que no hay diferencia entre forma y contenido. Todo esto indicaria que el arte clásico sería definitorio respecto a todas las posibilidades del arte. Y, sin embargo, eso no es así. Todas las representaciones de los dioses son perfectas y, justo por eso, no se puede

13 Ibid., pp. 44.45

14 Ibid., p. 62. 
jerarquizar y estatizar la representación clásica como el modelo definitorio del arte. En las representaciones clásicas no hay unidad, por el contrario, lo que hay es el desarrollo de muchos dioses que son indispensables, por lo tanto, no hay un solo poder ni una sola norma, sino la constante de la diversidad llevada, en cada una de sus representaciones, a la perfección.

Por último, habrá que mencionar otro rasgo capital a lo clásico que Hegel anota, el hecho de que el paso del arte simbólico al arte clásico haya sido un tránsito regido por la fantasía y la imaginación. Literalmente, el tránsito descrito en la literatura griega y plasmado en las esculturas de los dioses revelaría que la verdad se alcanza a través de principios formales de la esfera artística. Para ver lo importante que es este punto basta comparar los medios de transformación del arte clásico con los medios del arte romántico:

Este nuevo contenido [nos dice Hegel en referencia al contenido romántico] no se hace valer como un revelar a través del arte, sino que está revelado para sí sin él, y se presenta en el terreno prosaico de la refutación a través de razones, en el ánimo y en sus sentimientos religiosos, sobre todo a través de milagros, del martirio, etcétera, en el saber subjetivo, con la conciencia de la oposición de todo lo finito frente a lo absoluto, el cual sale a luz en una historia real como un discurrir de los hechos para alcanzar un presente no sólo representado, sino además fáctico. ${ }^{15}$

Son pues, dos rasgos los fundamentales respecto al arte clásico que se pueden leer en la cita de Hegel, por un lado, en el desarrollo de las figuras del espíritu, la verdad ya no se alcanzará de acuerdo a los códigos del arte, sino a los códigos de la razón y de la fe religiosa; por el otro, el arte romántico, centrado en el cristianismo, logra hacerse presente por completo en la realidad. La historia del Dios cristiano es una "historia real", por lo tanto ya no es una historia representada donde tenga que hacerse alguna interpretación del pasado:

El verdadero contenido de lo romántico es la interioridad absoluta, y la forma correspondiente es la subjetividad espiritual como aprehensión de su autonomía y libertad. Esto, que es infinito y universal en y para sí, constituye la negatividad absoluta de todo lo particular, la simple unidad consigo, que ha consumido todo estar lo uno fuera de lo otro, todos los procesos de la naturaleza y su ciclo de nacer, perecer y renacer, toda limitación de la existencia espiritual, y ha disuelto

${ }^{15}$ Ibid., pp. 79-80. 
todos los dioses particulares en la pura identidad infinita consigo. En este panteón están destronados todos los dioses, los ha destruido la llama de la subjetividad; y el arte, en lugar de los muchos dioses plásticos, ahora sólo conoce un Dios, un espíritu, una autonomía absoluta. ${ }^{16}$

Intentemos enunciar los rasgos de lo clásico que nos son fundamentales para nuestra investigación:

a) Lo clásico se significa y se interpreta a sí mismo, esto es, lo clásico representa un momento del espíritu objetivo donde el ser humano realiza representaciones y creaciones libres y autónomas.

b) En tanto lo clásico se sabe consciente de sí, lo clásico se muestra. Ejemplifiquemos con el caso de la tradición. La tradición es pública, está ahí presente y manifiesta del mismo modo que aquello que Hegel llama el espíritu objetivo.

c) Es esencial al modelo de lo clásico el politeísmo. En ese sentido, existe una divinidad intuida y representada de forma inmediata.

d) Justamente por la tensión entre la mera intuición y la formulación de conceptos es que bajo el modelo de lo clásico no logra formarse una "totalidad sistemática articulada". Un sistema necesita de la configuración conceptual: no puede haber sistematicidad conceptual en lo clásico mientras se manifieste en su percepción del mundo una divinidad inmediata e intuitiva.

e) En el modelo de lo clásico no se constituye una "historia real" de facto en el sentido del realismo moderno, sino la representación de una historia en el presente a través de fantasías e imaginarios.

$f$ El modelo clásico nunca está del todo presente; justamente el hecho de que su develación esté contaminada de imaginarios implica que no está cerrada sino, por el contrario, que el hecho de lo clásico necesita de constantes interpretaciones creativas en el presente.

\section{La carencia de lo clásico}

En las notas anteriores pueden observarse ya los inconvenientes que conlleva el asumir lo clásico como modelo normativo desde una perspectiva crítica y moderna; sin embargo, dejemos todavía que sea Hegel el que nos indique por qué, desde su perspectiva, lo clásico debe de ser trascendido. Para Hegel, al estar ausente de lo clásico la proyección de la razón absoluta, no se

${ }^{16}$ Ibid., p. 95. 
logra ni la profundidad necesaria que implica la vida ni se consigue, por lo tanto, ninguna reconciliación real del ser consigo mismo. Desde mi punta de vista, serían tres los elementos principales que la representación clásica de la vida no logra alcanzar según Hegel: la configuración del individuo a través de la subjetividad; la trascendencia de la finitud por la infinitud de lo absoluto, representada en el Dios cristiano; y, lo que Hegel maravillosamente señala con una metáfora cuando dice que a las grandiosas esculturas griegas les falta la mirada, la experiencia fundamental del dolor y su conciencia de salvación. En ese sentido Hegel dice:

[...] en el arte clásico la sensibilidad no está matada y muerta, pero tampoco ha resucitado a la espiritualidad absoluta. Por eso, el arte clásico y su religión bella no satisfacen las profundidades del espíritu. Por concreto que sea este arte en sí mismo, permanece abstracto para el espíritu. En efecto, su elemento no es el movimiento y la reconciliación de la subjetividad infinita, reconciliación lograda desde la oposición, sino la armonía imperturbada de la libre individualidad determinada en su existencia adecuada. Su elemento es esta quietud en su realidad, esta felicidad, esta satisfacción y grandeza en sí mismo, esta eterna hilaridad y felicidad, que incluso en la desdicha y el dolor no pierde el seguro descansar en sí. El arte clásico no ha elaborado en todas sus profundidades la oposición, fundada en el absoluto, y no la ha reconciliado. ${ }^{17}$

\section{Lo clásico como norma y como descripción}

El avance histórico de la dialéctica de Hegel implica hacer una separación, muy sutil, entre el funcionamiento de los conceptos como instrumentos de descripción temporal y como elementos normativos. Todo concepto, en tanto intuición y movimiento de una razón histórica determinada, tiene la función de señalarnos los límites de una época y el espíritu de esa época; sin embargo, en el momento en que la razón se sabe razón absoluta se vuelve autoconsciente de sí, en ese momento la razón trasciende la temporalidad y el espíritu de la época, para avanzar hacia la única normatividad válida: la de razón que conduce el proceso histórico. En ese sentido es que el arte siempre es pasado, pues una y otra vez es excluido del presente donde lo único que tiene la posibilidad de ser absoluto es la razón: "Toda la historia del arte está separada de la verdad del concepto. Forma parte, como todas las demás

17 Ibid., p. 18 . 
figuras históricas del espíritu, de las prefiguraciones del espíritu uno y único, consciente de sí mismo, que se consuma para Hegel en el concepto filosófico". ${ }^{18}$ Todo esto va constituyendo los muy comunes prejuicios frente al arte, por ejemplo, el de la falta de verosimilitud de todo arte.

Hegel es realmente en muchos sentidos un autor canónico. Simplemente su recorte de la historia de la estética sigue siendo modelo a seguir de mane. ra fiel en los estudios sobre arte. En cierto sentido, parece imposible que estemos hablando de textos producidos en el siglo XIX, obras recientes en la historia de la humanidad, cuando su influencia llega a ser prácticamente inapelable. El asunto puede explicarse debido a lo revolucionarios que llegan a ser los escritos de Hegel, éstos no sólo contienen una alta dosis de violencia sobre lo real, sino que además marcan una direccionalidad inequívoca que implica clausurar la interpretación de la historia para seguir adelante. Por ejemplo, pocos momentos tan radicales con respecto a la historia de la estética como aquel donde Hegel señala que "el arte clásico pasó a ser la representación del ideal adecuado al concepto, la consumación del reino de la belleza. No puede haber ni hacerse algo más bello" ${ }^{19} i Q u e ́$ implica esa afirmación de Hegel? Entre otras cosas, señala que el ideal de la belleza es un ideal temporal e histórico, que ha tenido su momento de realización y que es necio seguir valorando el arte desde una norma pasada que se explica en un momento histórico determinado. No es, pues, casual la importancia de Hegel en la historia del pensamiento. Él muestra los resultados de la historia desde el mirador de la autoconciencia de la razón, en ese sentido no se diferencia mucho de la soberbia que caracteriza a todos los pensadores canonizados de la modernidad, sin embargo, Hegel, dentro de ese selecto grupo de pensadores, es de los pocos que reconstruye históricamente el camino de la razón. Otros pensadores no tienen necesidad de decirnos sobre la historia de su categorías estéticas, morales o religiosas, Hegel lo hace, y esa sola acción propicia la vitalidad de su teoría. En Hegel, el momento de escribir la historia es el momento de la formación de la razón.

La historia que se narra desde la dialéctica moderna, y que contiene un sentido marcado por la razón, la cual se va desdoblando en figuras internas justo por su paso en el tiempo, se va llenando de cadáveres. Mientras más avanza la razón histórica, la estela que deja se va configurando como un pasado absoluto que no puede ya regresar jamás a la historia contemporánea. A hi es cuando lo que era una diferencia sutil entre nociones normativas y nociones descriptivas o estilisticas se radicaliza. A hora todo lo que queda

${ }^{18}$ H.G. Gadamer, "Hegel y el romanticismo de Heidelberg", en La dialéctica de Hegel. Trad. de Manuel Garrido. Madrid, Cátedra, 1994, p. 124.

${ }^{19}$ G. W. F. Hegel, op. cit., p. 93. 
tras la historia ya sólo es una noción de estilo sin ninguna posibilidad normativa. Dice Gadamer:

Puesto que esta forma del espíritu [el modelo clásico] es ya pasada, sólo puede ser ejemplar en un sentido limitado. Como arte pasado atestigua el carácter de pasado del arte mismo. Con esto Hegel justifica sistemáticamente la historización del concepto de lo clásico e introduce una tendencia que acabaría concibiendo lo clásico como un concepto estilístico y descriptivo, el de una armonía relativamente efimera de mesura y plenitud, media entre la rigidez arcaica y la disolución barroca. ${ }^{20}$

Dentro de la época moderna, topos de la primacía del método, del uso sistemático de la crítica y de la configuración de la conciencia por medio de la razón histórica, la única normatividad posible es la del discurso racional configurado con las características señaladas. En ese contexto es que habrá que concluir, a contracorriente de la modernidad, señalando las posibilidades de normatividad de lo clásico.

\section{La norma de lo clásico}

Para la conciencia moderna lo clásico no sólo deberia de tener pocas posibilidades de normativizar la realidad, sino que en el despliegue fascinante de los prejuicios ilustrados, lo clásico aparece en su pretensión de normativizar como un concepto ruinoso, que presupone a su interior principios esenciales de belleza que están más allá de cualquier interpretación histórica; por lo tanto, lo clásico se muestra como una noción esencialista y ahistórica que debe de ser fustigada. De ahí, que la noción de lo clásico en el sentido común de la crítica se asocie inmediatamente a la noción de lo canónico. ${ }^{21} \mathrm{La}$ única posibilidad de representación y enfrentamiento a la realidad por me-

${ }^{20}$ H.-G. Gadamer, Verdad y método I, p. 355.

${ }^{21}$ Es necesario hacer un deslinde entre el concepto de lo clásico y la elaboración de un canon. El canon es una especie de regla a la cual se debe de ceñir determinado proceso creativo. Señala Abbagnano que Epicuro "denominó canónico a la ciencia del criterio, que para él es la sensación del dominio del conocimiento, y el placer en el dominio práctico"; posteriormente, el término es utilizado por los matemáticos del siglo xvirI para señalar el uso adecuado de las reglas; y es con Kant cuando el término adquiere la connotación de uso recto de una facultad humana, de donde lo canónico llega a expresarse perfectamente en los criterios lógicos ya que estos prescinden de todo contenido. (Nicola Abbagnano, Diccionario de filosofía. México, 
dio de lo clásico, desde la perspectiva reflexiva de lo moderno, sigue siendo la misma que describiera Hegel, la quietud y la felicidad, la certeza de que somos invulnerables frente al sentido trágico de la vida. Tras lo clásico estaría un espiritu que nos hace comprensivos ante lo trágico, porque finalmente, como también indicara Hegel, lo clásico no alcanza realmente a experimentar el desgarramiento de toda vida. En lo clásico no hay culpa alguna. Por ejemplo, cuando Bolivar Echeverría hace un análisis de las formas de enfrentar el fenómeno del capitalismo en la modernidad sigue esa definición de lo clásico:

Vivir la espontaneidad de la realidad capitalista como el resultado de una necesidad trascendente, es decir, como un hecho cuyos rasgos detestables se compensan en última instancia con la positividad de la existencia efectiva, la misma que está más allá del margen de acción y de valoración que corresponden a lo humano; ésta es la tercera manera de hacerlo. Es la manera del ethos clásico: distanciada, no comprometida en contra de un designio negativo percibido como inapelable, sino comprensiva y constructiva dentro del cumplimiento trágico de la marcha de las cosas. ${ }^{22}$

En ese contexto, no deja de ser sorprendente la siguiente afirmación de Gadamer respecto de lo clásico: "En el fondo lo clásico no es realmente un concepto descriptivo en poder de una conciencia histórica objetivadora; es una realidad histórica a la que sigue perteneciendo y estando sometida la conciencia histórica misma". ${ }^{23}$ Para entender en toda su complejidad la cita de Gadamer habrá que tocar un tema capital de la filosofia. Si hemos rozado

FCE, 1993, pp. 139-140.) Por otra parte, la elaboración de un canon no está por fuera del hecho interpretativo. Sostener un canon implica ya un ejercicio interpretativo, por más que se quiera ver en el canon una esencia suprahistórica y una absurda pureza disciplinaria. Véase lo que significa el canon como arma y triste aduana en manos del famoso crítico Harold Bloom: "Ningún movimiento originado en el interior de la tradición puede ser ideológico ni ponerse al servicio de ningún objetivo social, por moralmente admirable que sea éste. Uno sólo irrumpe en el canon por fuerza estética, que se compone primordialmente de la siguiente amalgama: dominio del lenguaje metafórico, originalidad, poder cognitivo, sabiduría y exuberancia en la dicción. La injusticia última de la injusticia histórica es que sus victimas no precisan otra cosa que sentirse víctimas. Sea lo que sea el canon occidental, no se trata de un programa para la salvación social". (El canon occidental. Trad. de Damián Alou. Barcelona, Anagrama, 1995, p. 39.)

${ }^{22}$ Bolivar Echeverria, "El ethos barroco", en Modernidad, mestizaje cultural, ethos barroco. México, El Equilibrista-UNAM, 1994, p. 20.

${ }^{23}$ H.G. Gadamer, Verdad y método I, p. 357. 
ya temas tan importantes como el carácter pretérito del arte, como la permanencia de la tradición en el presente o como el fin de la historia, el siguiente punto hacia el cual me parece que se encamina Gadamer no deja de ser nodal. El punto remite a la existencia de una conciencia moral en el sen. tido de lo moderno.

Cuando determinadas teorias han insistido en formularse por fuera de una configuración moral de la vida, en muchos casos, no se han entendido los alcances históricos y hermenéuticos de pensar la realidad desde esta premisa. Pasa lo mismo con Gadamer y el farragoso debate entre un planteamiento ontológico y un planteamiento ético. El problema en principio no deberia de ser abordado de una manera academicista, esto es, no debe de estar rodeado de sinuosas categorías disciplinarias que de antemano presentan a los fenómenos domesticados para su análisis. El problema más bien es, en última instancia, el problema de una conciencia histórica muy particular y determinada, el de la conciencia fundamental de la modernidad: la conciencia cristiana y su desarrollo en conciencia critica. El asunto puede plantearse de la siguiente manera: si uno considera que la conformación de lo humano planteada por el cristianismo es la única posible, esto es, la de la humanidad universal y monoteísta, entonces uno puede defender una y otra vez la existencia de la conciencia moral en el principio y por el fin de los tiempos. Si en cambio, uno reconoce que hay fenómenos que se contraponen al dictum de reglas morales desde la subjetividad, reglas que se imponen desde una forma universal y un desarrollo del monoteísmo elaborada desde el romanticismo cristiano, como, por ejemplo, el fenómeno del politeísmo o la intuición de la divinidad como en lo clásico; entonces se puede plantear la existencia de formas de conciencia que no respondan necesariamente a la formación de una conciencia moral subjetiva. No toda manifestación de la conciencia debe de ser entendida como la manifestación de una conciencia moral del sujeto. De esa forma me parece que Gadamer pretende leer la permanencia de lo clásico en el fenómeno de la comprensión: no siempre existe un elemento subjetivo rector en las sociedades ni sólo hay una constitución perfecta de la historia por medio de la razón absoluta y, en ese sentido, formas como la conciencia histórica que remite de manera primordial a la conciencia moral del cristianismo puede seguir estando sometida por movimientos más elementales e intuitivos, como el de lo clásico que se representa en la forma de mediación entre la tradición y el presente.

Ninguna historia, por muy duradera que sea, como por ejemplo, la historia del imperio romano, por muchos elementos de control de la realidad que posea, por ejemplo, la época de la tecnologización o por muy privilegiada que se encuentre en el momento de interpretar, por ejemplo, la historia pre- 
sente, puede dejar fuera de sí a los rasgos constitutivos de la comprensión diversa del ser en la historia. Esa historia, la de la comprensión del estar en el mundo, es inconcebible para una interpretación finita, pero eso no quiere decir que no se encuentre presente, actuando de tal modo que en muchas ocasiones no se manifiesta de manera consciente. La permanencia de lo clásico, en ese sentido, responde más a la forma en que son hombres y mujeres en el momento de comprender, que a una noción historiográfica:

[...] lo clásico es una verdadera categoría histórica porque es algo más que el concepto de una época o el concepto histórico de un estilo, sin que por ello pretenda ser un valor suprahistórico. No designa una cualidad que se atribuya a determinados fenómenos históricos, sino un modo característico del mismo ser histórico, la realización de una conservación que, en una confirmación constantemente renovada, hace posible la existencia de algo que es verdad. ${ }^{24}$

Hegel sigue teniendo la razón cuando dice que lo clásico es aquello que se interpreta y se significa a sí mismo. Lo clásico es la parte del pasado que se encuentra diciéndole algo a cada presente, como señaló Gadamer. Lo clásico contiene a su interior una incesante mediación que lo coloca en el presente, pero que no le hace ser presente, ningún presente es clásico. Para que algo sea clásico tiene que ser validado por el tiempo, tiene que trascender la subjetividad individual y tiene que conformarse a sí mismo a través de la historia y de la interpretación de cada presente. Ninguna conciencia puede señalar qué es o qué no es clásico, sino que lo clásico mismo orienta el juicio de la conciencia. En el fondo, lo que se revela con la posibilidad de normatividad de lo clásico es la vulnerabilidad de lo moderno. La noción de la modernidad univoca y dominante, progresiva y segura de sí misma, aparece como una figura falsa. Por el contrario, lo que existe es una constante mediación entre nuestro presente y el pasado. En esa mediación nuestras creencias juegan frente a otras creencias que están constituidas ya como clásicas por el simple hecho de trascender su carácter de pasado estático y convertirse en un pasado activo y presente. Lo clásico es prácticamente todo, porque todo está inundado de los referentes del pasado en el hecho de com. prender. ${ }^{25}$ De ahí, que poco valga lo clásico como concepto autónomo o como regla normativa que se asemeje en su funcionamiento a la norma de la razón absoluta. Como señala Gadamer, la "elucidación del concepto de lo

${ }^{24}$ Ibid., p. 356.

${ }^{25}$ Esta idea, manifestación de la intuición del intérprete, la oí, y la debo, a una plática con Mariflor Aguilar. 
clásico no pretende para sí un significado autónomo, sino que intenta suscitar la pregunta de si esta mediación histórica del pasado con el presente, tal como la realiza el concepto de lo clásico, no estará presente en todo comportamiento histórico como sustrato operante" ${ }^{26}$

El tipo de normatividad que se realiza desde lo clásico es el de la representación de una constante norma débil, que lo único que nos muestra es que todo ejercicio de comprensión se da en un movimiento entre los fines del presente y el sustrato que viene del pasado y que condiciona y nos indica las formas de comprensión del presente. "El comprender debe de pensarse menos como una acción de la subjetividad que como un desplazarse uno mismo hacia un acontecer de la tradición, en el que el pasado y el presente se hallan en continua mediación". 27

Sin embargo, el hecho de que el pasado siempre permanezca entre nosotros por sí mismo, regido por ese movimiento interno y autónomo que hemos ejemplificado con el fenómeno de lo clásico, no debe de hacernos creer que la permanencia del pasado es cosa fácil. El pasado permanece en tanto se re-interpreta a sí mismo y hace valer su voz ante las pretensiones del presente y las proyecciones de toda experiencia de vivir. El pasado, al igual que la tradición, vale en tanto siempre es contextual, es finito en su interpretación y es otro diferente a nosotros. La conciencia histórica de la modernidad dominante, aquella que confía ciegamente en la razón absoluta para conseguir sus fines, elimina la diversidad de la interpretación y evita la voces que no puede atrapar. Contra esa manifestación de la razón utilitaria y univoca hay que intentar, una y otra vez, darle densidad, a través de otra forma de conciencia, de crítica y de narración histórica, a la permanencia del pasado.

${ }^{26} \mathrm{H}$.G. Gadamer, Verdad y método I, p. 360.

${ }^{27}$ Ibid., p. 369. El original en alemán: "Das Verstehen ist selber nicht so sehr als eine Handlung der Subjektivität zu denken, sorden als Einrücken in ein Überlieferungsgeschehen, in dem sich Vergangenheit und gegenwart beständ vermitteln". Citamos el original para destacar la palabra Überlieferung, que no sólo tiene el sentido de tradición sino también el de transmisión. En ese sentido, Überlieferungsgeschehen puede traducirse como el acontecer de la tradición, pero también, en un sentido más débil, como el acontecer de algo trasmitido. De tal suerte que, pese a que la segunda traducción no es muy afortunada en español, sí permite obser. var con mayor claridad que la normatividad clásica no implica un rasgo esencialista de la tradición, sino simplemente acentúa una forma de mediación en el tiempo, la que se ejemplifica con lo clásico, y que implica la autonomía del pasado para colocarse por sí mismo en el presente, es decir, sin la mediación despótica de la razón absoluta, del concepto y de la conciencia subjetiva. 